\title{
Acknowledgement to reviewers of Vessel Plus in 2019
}

\author{
Vessel Plus Editorial Office \\ OAE Publishing Inc., Chaoyang District, Beijing 100016, China.
}

Correspondence to: Vessel Plus Editorial Office, OAE Publishing Inc., Rm. 968, 9th Floor, Xinhengji International Building, No. 3 Maizidian West Road, Chaoyang District, Beijing 100016, China. E-mail: editorialoffice@vpjournal.net

How to cite this article: Vessel Plus Editorial Office. Acknowledgement to reviewers of Vessel Plus in 2019. Vessel Plus 2020;4:1. http://dx.doi.org/10.20517/2574-1209.2020.06

Received: 19 Jan 2020 Accepted: 19 Jan 2020 Published: 21 Jan 2020

Science Editor: Mario F. L. Gaudino Copy Editor: Jing-Wen Zhang Production Editor: Jing Yu

The editors of the journal Vessel Plus (VP) would like to take this opportunity to express their sincere gratitude to the following reviewers for assessing manuscripts in 2019 [Table 1].

Table 1. The reviewers in 2019

\begin{tabular}{llll}
\hline Names & & & \\
\hline Antonitsis, Polychronis & Franco, Antonino Di & Lee, Lik Chuan & Sampaolesi, Maurilio \\
Anukam, Kingsley & Fremes, Stephen E. & Leone, Antonio Maria & Santos, Raul D. \\
Bedogni, Francesco & Fujikura, Kana & Maranhão, Raul C. & Sazonova, Margarita \\
Bharadwaj, Dwaipayan & Gambardella, Ivancarmine & Massimo, Chello & Shalimova, Anna \\
Butterworth, John F. & Garattini, Enrico & Miñana, Gema & Shinoda, Kenta \\
Caparros-Martin, Jose A. & Gaudino, Mario F. L. & Mohapatra, Chandan Ray & Siddiqui, Tariq \\
Chambers, David & Genco, Caroline Attardo & Muramatsu, Toshiya & Sobenin, Igor A. \\
Chello, Massimo & Golukhova, Elena & Nardi, Paolo & Sokolis, Dimitrios \\
Chen, Ying-Fu & Hasaniya, Nahidh & Nurbaev, Serik D. & Sticchi, Alessandro \\
Cordero, Alberto & Hirao, Shingo & Orban, Martin & Tan, Joannetm \\
Davidavicius, Giedrius & Isayeva, Anna & Ota, Takeyoshi & Tang, Dalin \\
de Groot, Eric & Jánosi, Rolf Alexander & Overtchouk, Pavel & Tascini, Carlo \\
Dimopoulos, Konstantinos & Jemtel, Thierry H. Le & Parvizi, Mojtaba & Tseng, Elaine E. \\
Dubrovskaya, Maria I. & Karagodin, Vasily & PAtrianakos, Alexandros & van der Linden, Jan \\
Dzīīite-Krišāne, Iveta & Kazubskaya, Tatyana P. & Petrova, Nika V. & Varaeva, Yu R. \\
Efremova, Olga A. & Kim, Deokho & Pollari, Francesco & Wang, Chunsheng \\
Falsini, Giovanni & Kirichenko, Tatiana & Qintar, Mohammed & \\
Fedorova, Tatyana & Koshin, Andre & Rahouma, Mohamed & \\
Formica, Francesco & Kurita, Tairo & Raja, Shahzad G. & \\
\hline
\end{tabular}

cc) (i) The Author(s) 2020. Open Access This article is licensed under a Creative Commons Attribution 4.0 International License (https://creativecommons.org/licenses/by/4.0/), which permits unrestricted use, sharing, adaptation, distribution and reproduction in any medium or format, for any purpose, even commercially, as long as you give appropriate credit to the original author(s) and the source, provide a link to the Creative Commons license, and indicate if changes were made. 
We greatly appreciate the contribution they made and the time they donated to the journal. They can get their Reviewer Recognition Certificates by building their peer review profiles either on Publons (https:// publons.com) or on ORCID (https://orcid.org/).

If you are interested in becoming a reviewer for $V P$, you are welcome to apply at https://vpjournal.net/ journal/vol_reviewer.

\section{DECLARATIONS}

\section{Authors' contributions}

Writing and revision of the article and approved the final version: Vessel Plus Editorial Office.

\section{Availability of data and materials}

Not applicable.

\section{Financial support and sponsorship}

None.

\section{Conflicts of interest}

All authors declared that there are no conflicts of interest.

\section{Ethical approval and consent to participate}

Not applicable.

\section{Consent for publication}

Not applicable.

\section{Copyright}

(c) The Author(s) 2020. 